\title{
El caso Emmy von N.: entre la mirada clínica y los juegos del lenguaje
}

\author{
Antonio Sánchez Antillón ${ }^{1}$ y Tania Carina Zohn Muldoon² \\ ITESO, México
}

En el presente escrito se analiza la escritura de Freud al presentar el caso Emmy von N. Se abordan los presupuestos de Freud en su presentación del caso y se toma como muestra de análisis tres de las sesiones consignadas en el texto. En estos descriptores mostraremos los tipos de actos de habla que hace Freud en su interlocución con la Sra. Emmy, en miras de evidenciar la perspectiva epistemológica y antropológica que sostiene Freud en su presentación de caso. En la discusión se delimita cómo la mirada médica comanda la presentación, descripción e interpretación de Freud, y cómo, en ese esfuerzo por alcanzar los estándares de cientificidad propios de su época, delinea los juegos del lenguaje en la relación amo-esclavo. Se hace dialogar el análisis textual del caso de Freud con lo dicho por los historiadores Foucault y Laín, y se presume en las conclusiones cómo Lacan sigue las huellas freudianas desde las coordenadas expuestas en este trabajo; desde la función del lenguaje y de la palabra creadora.

Palabras clave: Freud, Lenguaje, Caso Emmy von N.

In this paper, Freud's work when presenting Emmy von N.'s case is analyzed. Freud's presuppositions in this case presentation are addressed, and three of the sessions contained in the work are taken as a sample of analysis. We will expose the speech acts found in Freud's interlocution with Mrs. Emmy, to highlight the epistemological and anthropological perspective that Freud holds in his case presentation. In the discussion, it is argued how the medical perspective guides Freud's presentation, description and interpretation, and how in his effort to accomplish the scientific standards of his time, he outlines the language-games within the master-slave relationship. The textual analysis of Freud's case is discussed with the sayings and statements of historians like Foucault and Lain, and it is assumed in the conclusions how Lacan follows Freud's traces from the inferences reached in this work, under the perspective of the function of language and the creative word.

Key Words: Freud, Language, Emmy von N. case

English Title: The Emmy von N case: between the clinical look and language games

\section{Cita bibliográfica / Reference citation:}

Sánchez Antillón, A. y Zohn Muldoon, T.C. (2019). El caso Emmy von N. Enmtre lamirada clínica y los juegos del lenguaje. Clínica e Investigación Relacional, 13 (2): 477-499. [ISSN 1988-2939]

[Recuperado de www.ceir.info] DOI: 10.21110/19882939.2019.130210

\footnotetext{
${ }^{1}$ Maestro de tiempo completo en el Instituto tecnológico y de Estudios superiores de Occidente (Universidad Jesuita en Guadalajara). Estudios en Licenciatura en Psicología por la Universidad Iberoamericana, Cd. De México; estudios de maestría en Teoría Psicoanalítica (CIEP); Doctorado por la Universidad de Ciencias Empresariales y Sociales (Argentina). Autor del libro Introducción al discurrir ético en psicoanálisis, y de varios capítulos de libro y revistas. Pertenece al Sistema Nacional de Investigadores (SNI 1). antonios@iteso.mx Tel. institucional: 36693442 ext. 3691.

${ }^{2}$ Académica de tiempo completo del Departamento de Psicología, Educación y Salud del ITESO. Formación: Licenciatura en Psicología en el ITESO. Especialidad en Psicoterapia Sistémica en el Instituto de Psicoterapia Sistémica de Occidente, de agosto de 1985 a mayo de 1988. Especialidad en Psicoterapia de Familias, en el Centro de Estudios Superiores y Atención a la Familia A.C. Maestría en Terapia Familiar Sistémica, Universidad del Valle de Atemajac. Doctorado en Educación, Universidad Marista de Guadalajara

CelR Vol. 13 (2) - Octubre 2019 ISSN 1988-2939 - www.ceir.info

(c) Derechos reservados/Copyright de Clínica e investigación Relacional y los autores. Prohibida la reproducción total o parcial sin autorización expresa. Este material es para uso científico y profesional exclusivamente y puede contener información clínica sensible. Los editores no se responsabilizan de los contenidos de los autores. Dirigir las consultas sobre derechos y autorizaciones a ceir@psicoterapiarelacional.es
} 


\section{Problematización}

El uso de la historia clínica constituye una parte del estudio del caso en psicoanálisis y arranca con la escritura que hace Freud al final de cada encuentro entre el médico y el paciente siguiendo los recuerdos del profesional que escucha. Posteriormente usa la información para pensar el caso y darle una explicación desde la teoría. Este saber sistematizado es el material que trasmite a los colegas de modo que se pueda utilizar para generar conocimiento. Freud es un pensador que inaugura un nuevo campo de conocimiento siendo un hombre de ciencia del siglo XIX y desde una perspectiva de formación, la neurología y la psiquiatría. Stake (1999), refiere que en la actualidad hay al menos tres usos del material en el estudio del caso, a saber: el intrínseco, que trata de ser analizado por el interés mismo del caso; el instrumental, que sirve para ilustrar un problema o teorizar; y el colectivo, que pretende contribuir a la construcción de un cuerpo teórico. Por su parte Nasio (2001), desde el campo psicoanalítico, refiere tres funciones en el estudio del caso: didáctica, metafórica y heurística. El uso del caso para la enseñanza tiene un potencial sugestivo por el despliegue escénico y figurativo, así como de dramatización por la antropomorfización que se hace de los conceptos utilizados. En ciertos casos típicos la observación sustituye el concepto transformándolo en una metáfora, se habla de casos típicos, como es el caso Schreber, que condensa el saber sobre el concepto de la psicosis paranoide. Finalmente, si el análisis da cabida a la emergencia o cuestionamiento de los conceptos se genera la fecundidad heurística del caso.

Nasio (2001) perfila con mucha claridad lo que ahora se entiende por estudio de caso, así como sus usos o funciones; sostiene que éste es concomitante al nacimiento del psicoanálisis. Los casos de Freud se han recuperado para mostrar con ello la construcción de los conceptos nacientes en el psicoanálisis. Por ello de vez en vez es bueno revisitarlos para pensar qué tanto el historial clínico, desde la mirada del médico, se fue conformando como un estudio de caso biográfico. Y para evidenciar cómo ciertas huellas del nacimiento del psicoanálisis siguen influyendo en los modos de pensar y trasmitir el caso en la actualidad.

Hay dos historiadores de la medicina y de la clínica que han ponderado la obra de Freud, uno es español y el otro francés. El primero, Laín (1958), refiere que desde la antigüedad el método y la mirada médica eran diferentes a la escucha psicagógica. Por ejemplo, en uno de los diálogos de Platón, El Cármides, se discierne cómo la atención de un mal físico puede deteriorar el ánimo, así como la situación moral del sujeto. De modo que la dialéctica socrática trata de delimitar los alcances y límites de cada cual. El médico-sacerdote asirio iniciaba su escucha sometiendo al enfermo a un interrogatorio ritual dirigido a la intimidad moral, que apela a la memoria de los actos del paciente. Por su parte en el cristianismo el 
principio es que el sujeto padece el mundo y los gastos del existir como parte del pecado de origen. Por lo que el logos o verbo de Cristo es el camino de purificación del alma y del cuerpo. Para lo cual debe ejercitarse el penitente en rememorar sus errores, evidenciar su condición pecaminosa, y dar cuenta de cómo sus actos hacen efecto en su padecimiento. Dos técnicas se desarrollaron a lo largo de los siglos, la confesión y los ejercicios de meditación acompañados por un director de almas.

Para Laín (1958), Freud es heredero tanto de la medicina Asiria como del uso dialógico del cristianismo, en ambas perspectivas antes de cualquier tratamiento se hace un llamado a las vivencias morales del sujeto. Pero, sobre todo, reconoce en Freud un corrimiento teórico que va de la neurología, basada en el método diagnóstico del ojo y el tacto, hacia la escucha del síntoma en la biografía. El método diagnóstico desde el siglo XVIII se basa en el interrogatorio del médico al paciente, se toma a este último como testigo del padecimiento.

Laín (1958) refiere ciertos desplazamientos gestados en la obra freudiana, a saber: la inferencia o conjetura del malestar pasa de la intuición eidética, por la forma o deformación del cuerpo, a la arqueología; la escucha va, de la testificación del padecimiento a la biografía; mientras que la revelación o anamnesis se basará en una conversación, en un estilo de dialéctica: se escucha la historia del paciente y el médico ofrece su interpretación sobre la narración del paciente.

La forma de consignar el caso pasó de la escucha médica que busca la construcción clínica del caso, al estudio biográfico. Ejercicio que lo llevó a crear una nueva tecnología de escucha que desplazó a la hipnosis: la curación por la palabra. Este inédito en el método está sostenido bajo una serie de supuestos propios del discurso hegemónico de la comunidad epistémica de la cual provenía Freud. De modo que, el ejercicio diagnóstico se trastoca, ya que de la anamnesis testifical se pasa a la anamnesis interpretativa; el juicio diagnóstico no sólo es enunciativo y descriptivo sino interpretativo, y se pasa del relato biológico a la "narración biográfica" (Laín, 1978a, p. 649). Con ello introduce la patografía que es antecedente de la patología biográfica actual. Y como bien dilucida Lothane, (1992), a la descripción histórica de la paciente le sumó una dramatología, aplicable a la relación interpersonal en trastornos en el área de la salud, las neurosis, así como para el dispositivo analítico ${ }^{1}$. Finalmente hay que decir que Laín (1978a), fecha la introducción del sujeto en la medicina por los escritos de Freud en 1886. Y que, aunados sus estudios a otros como el trabajo en la Salpétriére, generan el fenómeno social que llama rebelión del sujeto.

Si bien, en otro de sus estudios reconocerá con Mr. Jourdain que, "[...] con la prosa, el psicoterapeuta hace retórica aristotélica sin saberlo. Claramente lo demostraría un análisis retórico de cualquiera de las historias clínicas de Freud" (Laín, 1978a, p. 257). 
El otro historiador atento al desarrollo freudiano es Michel Foucault. Los estudiosos afirman que Foucault tiene un discurso ambiguo, ya que por un lado reconoce en Freud superar la mirada clínica del siglo XVIII y por otro lo coloca como parte de la observación que objetiva unidireccionalmente al paciente.

La lectura que se hace en este escrito es que Foucault ofrece atributos distintos dependiendo del estudio que realiza. En La microfísica del poder reconoce su intención investigativa, a saber: hacer una genealogía del psicoanálisis. En La Historia de la locura (1998a; 1998b) coloca a la escritura freudiana en el lindero entre la episteme de los siglos XVIII y XIX. Por lo que reconoce que en el método de escucha innova al médico del siglo XVIII cuando le da la palabra al paciente y escucha la causa eficiente del padecimiento en los fantasmas de las pacientes; voz acallada por el pensamiento psiquiátrico. Aunque Freud es consecuente con el clínico de ese siglo cuando al presentar sus casos muestra un monólogo indefinido y vigilado, sostenido en silencios interpretados por el médico con pretensión de poder-verdad. Y mientras, usa la ciencia de las enfermedades mentales que se sostiene en la "ciencia de la observación y de la clasificación" (Foucault, 1998b, p. 228). Con ello Freud prolonga el ejercicio del poder de la vigilancia y enjuiciamiento del asilo. También precisa en su Historia de la sexualidad, Voluntad de saber que la propuesta freudiana de los Tres ensayos no es sino la conclusión de un desarrollo que se venía cultivando sobre la scientia sexualis. Por lo que el concepto de represión, y su explicación económica y dinámica de la libido, consolida la idea de que se trata de algo a vigilar y hace suponer que hay una verdad del sexo, la cual debe ser confesada para su liberación. Foucault (1996a), contrapone a esa perspectiva, evidenciar la verdad y el poder concomitante en tal pretensión como recorrer el foco de análisis de la represión de la sexualidad, a pensar cómo se hace la producción de ella. Y en otro estudio, critica de idealistas las pretensiones conceptuales de universalidad del Edipo, refiere que: "Si hay algo parecido a un complejo de Edipo, este no se da a nivel individual sino al nivel colectivo; no a propósito del deseo y el inconsciente sino a propósito del poder y del saber" (Foucault, 1996b, p. 39). Cuando contrasta las epistemes y precisa el uso del método como en Las palabras y las cosas (1995) y, en Nietzsche, Marx y Freud (1970), reconoce al psicoanálisis como diferente de la psicología, porque toma al lenguaje como objeto de estudio. También sostiene que la pretensión teórica explicativa del sujeto basada en conceptos psicoanalíticos que pretenden ser generalizables a toda cultura olvida un asunto fundamental: que todo signo ya está cargado de sentido. Finalmente, en las Tecnologías del yo (1996b), reconocerá que el psicoanálisis es heredero de las escuelas filosóficas como la de Epicteto, donde se propone analizar las representaciones como monedas de cambio.

Como se ve ambos historiadores reconocen que Freud innova al médico del siglo XVIII, "[...] al tomar la locura al nivel de su lenguaje" (Foucault, 1998a, p. 529), y al incluir la narración 
biográfica e introducir al sujeto en la patografía (Laín, 1958; 1978a). No obstante, también reconocen que es heredero del modelo médico que dio consistencia a la práctica psiquiátrica del asilo y la patología biográfica. Del mismo modo, coinciden cuando refiere Laín (1978b) que Freud realiza retórica aristotélica sin saberlo, y en ese estilo de escritura del caso freudiano, Foucault coloca el reto para el futuro del psicoanálisis, pues refiere que:

La ciencia de las enfermedades mentales, tal y como puede desarrollarse en los asilos, no podrá ser nunca más que ciencia de la observación y clasificación. Ello no será un diálogo. Y no podrá serlo verdaderamente sino hasta el día en que el psicoanálisis haya exorcizado el fenómeno de la mirada, esencial en el asilo del siglo XIX, y que haya sustituido su magia silenciosa por los poderes del lenguaje (Foucault ,1998b, p. 228).

\section{Planteamiento}

Siguiendo estas inquietudes mostradas por los historiadores, el objetivo del presente trabajo es analizar el caso Emmy von N. presentado por Freud (1894-95/1985) al inicio de sus primeras investigaciones sobre la histeria. Se focaliza la pesquisa en cómo, al ir presentando la información, hace uso de preguntas o indicaciones verbales; se mostrará qué cosas hace con palabras ${ }^{2}$ en el caso que presenta.

Dado que queremos develar qué dice, qué hace Freud en su trabajo inicial de hipnotista al presentar el caso, se recurre al método de análisis del texto sostenido en la teoría de los actos del habla, en la ontología del lenguaje (Echeverría, 2003); basados en la perspectiva del giro lingüístico (Santander, 2011). Después se discute el análisis de este caso con las afirmaciones que hacen sobre la posición epistémica y antropológica de Freud, Foucault y Laín. Al final de este trabajo se exponen las conclusiones.

\section{Observaciones de Freud al caso Emmy, previo a su análisis}

Uno de los primeros casos que Freud analiza es el de Emmy von N., con quien reconoce ejerció por primera vez la hipnosis. Antes de describir las notas de sus sesiones hace ciertas observaciones, las cuales mostramos a continuación.

Al inicio de la escritura del caso, Freud hace un franco reconocimiento de su novatez en el ejercicio de la hipnosis y de no seguir concienzudamente un debido plan el análisis de los síntomas patológicos. Además, expresa que presentará el estado de la enferma y su proceder médico redactando su intervención y los efectos de ésta. Aclara que las notas al pie son dilucidaciones posteriores en fecha que permiten inteligir de mejor manera el tema. 
Siguiendo los protocolos propios del cuadro diagnóstico describe la historia familiar de la paciente. Precisa el desencadenamiento de la enfermedad a raíz de la muerte de su marido. Es sumamente descriptivo respecto a la condición de sus padecimientos físicos y los diversos tratamientos que se le han aplicado a la enferma. Pondera que es una persona susceptible para la hipnosis en tanto que al poner el dedo en su frente y a la orden de "duérmase" ella se abandona estupefacta y turbada.

En el siguiente cuadro se fragmenta lo expuesto por Freud en miras de evidenciar cómo la introducción al caso ya está preñada de sentidos. En el cuadro se muestran tres columnas, la primera es la frase textual, en la segunda el tipo de frase que se califica desde la teoría de los actos del habla y en la tercera se expresa el término, a la letra, que refiere Freud a lo dicho en la primera columna.

Observaciones de Freud al caso, previo a su análisis. Cuadro 1: Análisis de los enunciados de Freud, en su presentación del caso (1895-95/1985).

\begin{tabular}{|c|c|c|c|}
\hline Frases & Qué dice Freud & Tipo de frase & $\begin{array}{l}\text { Sentido asumido en } \\
\text { conceptos }\end{array}$ \\
\hline 1 & $\begin{array}{l}\text { "Para que pueda visualizarse } \\
\text { el estado de la enferma y mi } \\
\text { proceder médico" }\end{array}$ & $\begin{array}{l}\text { Frase declarativa cuyo sentido } \\
\text { principal recae en la preposición } \\
\text { que indica propósito: "para que" }\end{array}$ & $\begin{array}{l}\text { Estado de la enferma } \\
\text { Proceder médico }\end{array}$ \\
\hline 2 & $\begin{array}{l}\text { "Fue mi primer intento de } \\
\text { manejar este } \\
\text { método terapéutico" }\end{array}$ & Declaración de situación concreta & Método terapéutico \\
\hline 3 & $\begin{array}{l}\text { "[...] no llevé suficientemente } \\
\text { adelante el análisis de los } \\
\text { síntomas patológicos, ni los } \\
\text { perseguí con el necesario } \\
\text { plan" }\end{array}$ & $\begin{array}{l}\text { Confesión y reconocimiento del } \\
\text { error propio }\end{array}$ & Síntomas patológicos \\
\hline 4 & $\begin{array}{l}\text { "Toda vez que mi posterior } \\
\text { experiencia me ha } \\
\text { proporcionado } \\
\text { una inteligencia mejor, lo } \\
\text { consigno en notas al pie o en } \\
\text { puntualizaciones } \\
\text { intercaladas" }\end{array}$ & $\begin{array}{l}\text { Advertencia, reconocimiento de } \\
\text { autocorrecciones }\end{array}$ & $\begin{array}{l}\text { Puntualizaciones } \\
\text { Intelecciones } \\
\text { posteriori }\end{array}$ \\
\hline 5 & $\begin{array}{l}\text { "Es notablemente apta para } \\
\text { la hipnosis }[\ldots . .] "\end{array}$ & Declaración e inferencia & Hipnosis \\
\hline $5 b$ & $\begin{array}{l}\text { "Le acerco un dedo, le digo } \\
\text { 'Duérmase' y ella se } \\
\text { abandona..." }\end{array}$ & $\begin{array}{l}\text { Argumentación vía ejemplificación } \\
\text { por medio de microrrelato referido } \\
\text { al sentido de la frase cinco } \\
\text { Acto directivo y acto declarativo } \\
\text { sobre el acatamiento de la orden o } \\
\text { indicación }\end{array}$ & \\
\hline
\end{tabular}




\begin{tabular}{|l|l|l|l|}
\hline $5 \mathrm{C}$ & $\begin{array}{l}\text { "Le había dicho que la } \\
\text { hipnotizaría, cosa que aceptó } \\
\text { sin resistencia..." }\end{array}$ & $\begin{array}{l}\text { Argumentación vía ejemplificación } \\
\text { por medio de microrrelato } \\
\text { subordinado al sentido de la frase } 5 \\
\text { Acto directivo y acto declarativo } \\
\text { sobre el acatamiento de la orden o } \\
\text { indicación dada }\end{array}$ \\
\hline $5 \mathrm{~d}$ & $\begin{array}{l}\text { "Acepta, sin objetar palabra, } \\
\text { mi propuesta de separarse de } \\
\text { ambas niñas..." }\end{array}$ & $\begin{array}{l}\text { Argumentación vía ejemplificación } \\
\text { por medio de microrrelato } \\
\text { subordinado al campo de sentido } \\
\text { de la premisa 5 } \\
\text { Acto directivo y acatamiento de la } \\
\text { orden o indicación }\end{array}$ & \\
\hline
\end{tabular}

Como se ve en este cuadro por el tipo de frase que usa Freud podemos inferir el propósito de la presentación de caso, el autorreconocimiento de la novatez en el uso del método terapéutico (frases 1 y 2), los límites de su método de presentación y tratamiento (frase 3) y lo provisorio de lo inteligido (frase 4). En la frase cinco hace un juicio de atribución diagnóstica sobre la paciente, la cual sostiene bajo microrrelatos en donde se destaca una coligación entre el acto directivo y su acatamiento. Esta concatenación genera un sentido mayor que permite evidenciar el supuesto de obediencia que debe el paciente al médico. En la columna cuarta se precisan los términos conceptuales, que enlazan con lo dicho en la columna uno. Los términos de enfermo, método terapéutico (hipnosis), síntomas patológicos refieren a la perspectiva médica de su tiempo. Con ello, se evidencian los supuestos que tiene Freud respecto a la asunción del lugar y función social entre médico y enfermo (así como del lugar relacional entre quien escribe y de quién se escribe). Lo anterior determina y justifica el método terapéutico y la perspectiva investigativa. Éste es el primer juicio de atribución ofrecido en la presentación del caso, dice: "Era histérica, y con la máxima prontitud caía en estado de sonambulismo; cuando reparé en esto, me resolví a aplicarle el procedimiento de Breuer de exploración en estado de hipnosis" (Freud, 1893-95/1985, p. 71). Es decir, la primera tarea de Freud acorde al contexto y fines asumidos desde su función de médico es diagnosticar siguiendo en todo momento los signos y síntomas para poder intervenir en miras de curar. Fiel a la mirada de la ciencia de su época toma como objeto de estudio al enfermo, por lo que el campo de sentido de sus expresiones verbales, paraverbales y expresiones corporales las va articulando con lo expresado en los relatos o los silencios que realiza la paciente. Estos signos, por la nominación que hace el profesional de su objeto como histérica (ser enfermo), posibilita pensar que todo lo narrado por ella es un dato a articular para justificar el diagnóstico (¿redundancia o tautología?). 


\section{Unidad o foco de análisis}

A continuación, se centra el análisis en la descripción que hace Freud en el inicio del tratamiento, en las sesiones consignadas los días 8, 9 y 10 de mayo. Se fragmentará su descripción a fin de evidenciar cómo hace cosas con palabras, guiados por las preguntas ¿qué dice? ¿qué mira?, ¿qué interpreta de las palabras y gestos de la paciente?, y ¿qué conjeturas o hipótesis explicativas hace?

La pesquisa de Freud se centra en tres frases que advierte desde la primera sesión de mayo, las cuales coloca como enigmas a resolver. Siguiendo su intencionalidad narrativa tomamos como foco de análisis estos tres días en los cuales describe la resolución del enigma narrativo.

\section{Foco de análisis}

En la nota del 8 de mayo Freud describe cómo narra la paciente historias terroríficas. Sobre todo, puntualiza sus gestos durante sus narraciones, sean de horror, asco o miradas de desconcierto o desorientación del espacio, así como los chasquidos, jadeos, tartamudeos y otros ruidos que hace con la boca. La atención de Freud se centra en tres frases: "¡Quédese quieto! ¡No hable! ¡No me toque!" (Freud, 1893-95/1985, p. 72), así como en la reacción afectiva de asustadiza que la enferma presenta ante la figura de imágenes de animales.

Bajo el influjo de la hipnosis en esta sesión Freud pregunta por su carácter asustadizo y la paciente le ofrece una serie de relatos de su niñez: su primer recuerdo del desmayo porque sus hermanos le arrojaban animales muertos; cuando fue asustada por su hermano quien estaba como fantasma debajo de una sábana; cuando vio en el sarcófago cómo se le cayó la mandíbula a su tía.

Freud ofrece a sus lectores dilucidaciones sobre estas escenas: afirma que comprende ahora por qué habla tanto de esas escenas con animales, y le confirma la hipótesis que tiene de que ella es impresionable y le afectan fuertemente las imágenes; dice: "me confirma que en el curso del relato ve frente a sí cada escena de una manera plástica y en colores naturales" (Freud, 1893-95/1985, p. 75). Posterior a ello, describe qué hace con eso mediante su técnica hipnótica: borrarle esas imágenes, para que no se presenten ante sus ojos. También hace conjeturas explicativas sobre el modo de narrar la serie de recuerdos, refiere que son propios de los períodos de la niñez de la paciente y están aprontados en su memoria.

Inicia la descripción de la sesión del 9 de mayo del mismo modo que las sesiones anteriores, cuenta el estado corporal de la paciente y sus condiciones sociales respecto a su relación con las hijas. Expone cómo se da el diálogo casual con la paciente antes de la hipnosis. La 
conversación del día anterior giró alrededor del periódico, este día sobre el atlas histórico cultural. Cuenta que la Sra. Emmy habla del terror que le da la imagen de indios disfrazados de animales: "imagínese que estuvieran vivos". Esta frase en un parafraseo similar, que declara la paciente en la sesión anterior: "imagínese que abran el paquete".

En la sesión de la mañana de este día, le pregunta Freud sobre el sentido de una escena desplegada y un acto para-verbal: la persistencia del terror de las imágenes de animales y el modo de hablar, su tartamudeo y su chasquido.

El tartamudeo lo atribuye Emmy a su enfermedad y el tic, a la escena de la enfermedad de su hija donde necesitaba estar en silencio. Freud le da las siguientes indicaciones para aminorar la significación del recuerdo: "no le sucedió nada a su hija"; le da una orden: "no tener miedo de las imágenes de los indios, más bien reírse de ellas a carcajadas y llamarme la atención sobre ellas". Sugestión que tiene el efecto esperado cuando despierta.

En la sesión del atardecer de ese mismo día vuelve a inquirir Freud sobre las vivencias que le hayan provocado terror. Le vuelve a ofrecer la Sra. Emmy, con prontitud, una serie de recuerdos: llevar a los quince años a su prima y a su madre al manicomio; una criada que narró que tuvo una patrona que también fue internada y quien describió escenas terroríficas en el interior del hospital: atarlos, zurrarlos etc. Y puntualiza Freud cómo esas narraciones las expresa con horror vivo, como si fueran actuales y las estuviera viendo con sus ojos. Además, describe gestos, reacciones corporales de crispación y horror, de la paciente. Freud vuelve a intervenir con sugestiones hipnóticas para rectificar sus representaciones sobre el manicomio.

Enuncia la paciente otra serie de recuerdos terroríficos, tales como: a los quince años encuentra a su madre tirada en el suelo por un ataque de apoplejía; a los diecinueve la encuentra muerta, con el rostro deformado. A esa misma edad encontró debajo de una piedra un sapo y perdió el habla durante horas.

Después de la descripción de esta sesión Freud, ofrece, como lo hizo el día anterior, la siguiente dilucidación: "[...] me convenzo de que ella sabe todo lo que ocurrió, mientras que en la vigilia nada sabe de eso" (1893-95/1985, p. 77).

En la sesión del 10 de mayo por la mañana vuelve a iniciar con la descripción del estado de la paciente. Y le llama la atención que, en la plática previa, durante su masaje, ante la pregunta por su desazón ella le ofrece "reminiscencias patógenas". Freud hace una dilucidación ante ello: "es como si se hubiera apoderado de mi procedimiento y aprovechara la conversación, en apariencia laxa y guiada por el azar, para complementar la hipnosis" (1893-95/1985, p. 78). 
Después sostiene que la frase no me toque, proviene de una serie de experiencias: la enfermedad del hermano por uso excesivo de morfina por los que tenía súbitos e inesperados ataques; de cuando un conocido enloqueció en su casa y la tomó en sus brazos $y$, finalmente, cuando una de sus niñas en un delirio de enfermedad la cogió tan fuerte que casi la ahoga.

Posterior a exponer los relatos pasa a hacer otra dilucidación sobre el cómo fueron narrados. Dado que fueron expresados en una sola oración, como si constituyeran un acto único dividido en cuatro actos, supone que los traumas fundamentales están entramados bajo las conjunciones como y los parciales usando la $y$.

En la sesión de la tarde vuelve a preguntar sobre el sentido del tartamudeo y aunque la paciente había dicho no saber, narra ahora lo siguiente:

Cómo cierta vez se desbocaron los caballos con el carruaje en que iban sentados los niños, y cómo otra vez yo viajaba con las niñas por el bosque en medio de una tormenta y el rayo cayó en un árbol justo frente a los caballos y los caballos se asustaron [...] (Freud, 189395/1985, p. 79).

Frente a este relato Freud hace una conjetura explicativa: tiene que permanecer quieta de lo contrario asustaría a los caballos.

Viéndola dispuesta la cuestiona sobre otros recuerdos plásticos a lo cual ella ofrece una colección, dice Freud, de vivencias. En la medida que ella relata Freud va haciendo algunas intervenciones, prohibiendo, extinguiendo, borrando el recuerdo mediante sugestiones hipnóticas.

\section{Análisis de la muestra}

En las sesiones presentadas encontramos una secuencia común, inician con un preámbulo, que contiene un encuentro previo a la sesión y en donde Freud expone el contexto del lugar en el que se encuentra con Emmy. Su descripción en el diálogo previo a las sesiones se centra en las reacciones corporales y paraverbales, así como en las frases que usa y el contenido. Después relata el intercambio dialógico con la enferma durante la aplicación del método hipnótico.

Inicia con preguntas basado en los actos verbales y paraverbales, las reacciones afectivas mostradas en los gestos o en el contenido de los relatos. Al exponer cómo ejecuta el método, intercala sus inferencias teóricas o descriptivas. Las frases que usa en la inducción hipnótica son diversas y tienen como objeto provocar que se hable del tema que le generó incógnita a 
Freud en las sesiones previas o en el encuentro de socialización. Las preguntas que hace refieren a la causa, por ejemplo: inquiere el porqué de sus gestos, de sus afectos o de la reiteración de frases como las que toma de unidad de análisis: “Quédese quieto! ¡No hable! ¡No me toque!" Otras preguntas apuntan al tiempo y contexto: ¿Cuándo? ¿Dónde? ¿Siempre? Unas más exploran el estado sintomático de la enferma: ¿qué le pasa?

La franqueza y orden discursivo del escrito de Freud permiten precisar siguiendo su literalidad el tipo de acto de habla que utiliza en su intervención psicoterapéutica y su propósito. Por ello en el siguiente cuadro, en las columnas uno y tres se toma la frase textual que expresa Freud en el escrito, y en la columna dos se califica la frase desde la teoría de los actos del habla.

Análisis de la muestra. Cuadro 2: actos del habla en la intervención

\begin{tabular}{|l|l|l|}
\hline Frase & Acto de habla & Efecto esperado \\
\hline Ordeno no tener miedo & Directivo & Para tranquilizar \\
\hline Tacho el dolor del estómago & Realización de una acción & Para tranquilizar \\
\hline $\begin{array}{l}\text { Explico el sentido de su fórmula } \\
\text { protectora }\end{array}$ & Realización de una acción & Para menguar sus recuerdos \\
\hline Prohibición del recuerdo & Directivo & Inhibe \\
\hline Borro los recuerdos & Realización de una acción & Mejora su estado general \\
\hline Remuevo & Realización de una acción & Restos de excitación \\
\hline Explico & Realización de una acción & No debe temer a lo nuevo \\
\hline Revoco la reminiscencia & Realización de una acción & $\begin{array}{l}\text { Quito la posibilidad de ver todas } \\
\text { esas cosas tristes, que asustan, } \\
\text { que dan asco }\end{array}$ \\
\hline $\begin{array}{l}\text { Prometo le quitaré los dolores y } \\
\text { las expectativas de desgracia }\end{array}$ & Compromisorio & \begin{tabular}{l} 
Para tranquilizarla \\
\hline Aduzco
\end{tabular} \\
\hline Reprendo & Realización de una acción & Para convencer \\
\hline
\end{tabular}

Freud entonces hace muchas cosas con palabras, unas cuando está tratando a la paciente, otras cuando declara sus hipótesis sobre los efectos que va generando y unas más cuando trasmite el caso.

Como se puede observar por las calificaciones dadas en la columna dos del cuadro 2, en el tratamiento, los verbos que utiliza son fundamentalmente verbos de acción, directivos y uno de compromiso. Lo que permite sostener que al igual que en el cuadro 1, Freud se coloca como el sujeto de la acción mientras al otro lo coloca como destinatario pasivo que debe 
acatar. Y cuando el paciente no ejecuta lo que el médico le dice, por ejemplo, que no borra sus imágenes o recuerdos o no los expresa cuando él se los pide, Freud hace un juicio de atribución: se resiste. Lo mismo sucede cuando la paciente no puede olvidar un recuerdo o no logra entender la ligazón de las vivencias en estado consciente. Sólo que aquí el juicio de atribución está referido a suponer que hay alguna causa interna que la hace olvidar o sofoca el recuerdo. En otro momento cuando le pide Freud a la paciente que le dé más ejemplos alrededor de los afectos de horror, la enferma responde con una serie de relatos consecutivos, casi en una misma oración, lo que sorprende y hace que se pregunte ¿por qué los expresa "compulsivamente"? En una y otra forma de respuesta el médico ofrece hipótesis interpretativas o teóricas, las primeras apuntan a explicar cómo funciona o qué utilidad tiene ese enlace verbal o narrativo en el sujeto. Por ejemplo, a propósito de las tres exclamaciones Freud interpreta que las usa como fórmulas protectoras destinadas a prevenir el retorno de aquellas vivencias. Por lo que interviene quitándole el afecto, el miedo (ordena elidir el afecto) y al no volver a surgir en su presencia supone que ya desapareció. O cuando evidencia que la enferma no se acuerda de los hechos más que en el estado hipnótico, Freud declara: "le convenzo que sabe todo lo que ocurrió" (disuade). Y cuando para su sorpresa la paciente ofrece una serie de relatos concatenados expresa: "La serie de ocasiones traumáticas comunicadas". $Y$ ahí pasa a inferir que es como si los recuerdos los tuviera muy inmediatamente, a punto de salir; véase en esta observación un indicio sobre el concepto: preconsciente. En estos dos ejemplos últimos, podemos ya presumir ciertas conjeturas de Freud, una es que el sujeto sabe más de lo que reconoce conscientemente, y dos, que los recuerdos tienen cierta concatenación que hace que surjan bajo ciertas coordenadas de similitud temática, sea por una frase que hace de incógnita o por un afecto que se enlaza con diversas vivencias. Otros descriptores del caso apuntan a la postura conceptual de un aparato tópico respecto al funcionamiento "mental" por ejemplo cuando dice: reproducciones de recuerdos e impresiones o reminiscencias patógenas. Estas interpretaciones teóricas como cuando enlaza ciertos síntomas o signos con la palabra histeria, tienen como fin argumentar los descriptores diagnósticos.

Esta forma de discurrir en la presentación del caso es propia del diagnóstico habitual del médico clínico que relaciona la descripción física con la inferencia; esta mirada va de Galeno al mecanicismo cartesiano y el panvitalismo parcelsiano y helmoltiano. Ya que como expone el historiador las pautas investigativas de los siglos XVI-XVIII, se basan en: "[...] fuerzas físicoquímicas o inertes, biológicamente regidas por una hipotética 'fuerza vital'"' (Laín, 1978a, p. 398). Y como precisa Foucault, respecto a la mirada clínica del Siglo XVIII: 
[...] la enfermedad se presenta al observador de acuerdo a síntomas y signos [...] se distinguen por su valor semántico, así como por su morfología [...] Tos, fiebre, dolor de costado y dificultad para respirar, no son la pleuresía misma- ésta no se ofrece jamás a los sentidos, "no revelándose sino bajo el razonamiento" [...] (1999, p. 131).

En Freud, va de la observación a la escucha testimonial del padecer, a lo que agrega la escucha de la historia del sujeto y los sentidos condensados en los símbolos expuestos en las narraciones, así como en el modo de enunciar, para después sostener la inferencia diagnóstica, en el concepto3.

En la técnica y las observaciones que va haciendo Freud al caso, vemos lo que Foucault (1999) advierte, no es un diálogo sino un monólogo descriptor de signos y síntomas. Al enlazar las viñetas con un campo de sentido diagnóstico, evidenciamos también lo que Laín (1978a) refiere como patografía.

Pero también evidenciamos, que Freud en el intercambio lingüístico con la paciente, se va fijando en las coordenadas propias del lenguaje, que desde Platón tomaban en cuenta en la dialéctica, a saber: el lexis y el logos, qué se dice y cómo lo dice. Y va articulando el sentido entre del relato con el uso prosódico y sintáctico del enunciado, los cuales además articula con el lenguaje corporal: gestos y movimientos, como con los entrecortados sonidos paraverbales. Las preguntas son propias de un hombre de ciencia clínica del siglo XVIII, le importa saber cuál fue el origen, cómo se suscitó el evento traumático, bajo qué condiciones espacio temporales, así como si la paciente reaccionó o no frente al fenómeno médico. Un elemento más a destacar en el estilo retórico de Freud al presentar el caso es que los relatos de la paciente se vuelven un modo de argumentación para sostener sus indicios diagnósticos.

\section{Discusión}

Al analizar esta muestra encontramos elementos propios del proceder médico del siglo XVIII, como detalla Foucault (1999) en el capítulo cinco de El nacimiento de la clínica. En él desarrolla tres elementos relevantes de la mirada clínica: a) lo indisociable entre signo y síntoma; una circularidad tautológica entre uno y otro, que da consistencia al hallazgo; b) la soberanía de la conciencia, por inteligir lo expresado en la naturaleza; c) el ser de la naturaleza es enteramente enunciable en su verdad.

Como hemos visto, Foucault critica de Freud su pretensión de verdad, propia de la ciencia del siglo XIX. Sin embargo, a favor de Freud hay que decir que es un innovador. Foucault 
critica desde nuevas coordenadas de validez propias del estructuralismo, y en su crítica también hay pretensión de verdad.

La innovación de Freud radica en construir un nuevo campo de saber con base en una nueva práctica. Y como todo pensador, aspira a cumplir los criterios de cientificidad propio de su época. Freud supera la mirada médica, la cual la enlaza a una escucha, y construye bajo las mismas coordenadas un nuevo proceso diagnóstico y explicativo: la patografía biográfica. Lo anterior se evidencia cuando declara que son los síntomas histéricos unos afectos y unos restos de excitaciones de influencia traumática sobre el sistema nervioso (Freud, 189395/1985). La palabra trauma bajo la semántica del campo médico la desplaza, la transfiere para explicar la afección psíquica. Esto se ilustra en la siguiente definición: "En el caso de la neurosis traumática, la causa eficiente de la enfermedad no es la ínfima lesión corporal; lo es, en cambio, el afecto de horror, el trauma psíquico". (Freud, 1893-95/1985, p. 31). Concordamos con Foucault que en esta definición hay una tautología, donde lo definido está en la definición. Este mismo estilo es evidente en la presentación que hace Freud del caso, como vimos en el análisis que se hizo en este artículo.

Desde esta lógica de construcción de sentido, al ir escuchando a Emmy va sumando las distintas vivencias bajo ciertas coordenadas o supuestos epistémicos, describiendo la diferencia, la simultaneidad, la sucesión del hecho y su frecuencia 4 . A esta mirada del cuerpo expuesto, le suma Freud la escucha de la historia, en la cual trata de pesquisar la relación existente entre los actos para-verbales de la paciente como el chasquido, el tic, el tartamudeo, en tanto se presentan en ocasiones parecidas y la emergencia de ciertas palabras o relatos. Su pretensión de ir a la causa última del mal, lo conduce a conjeturar desde distintos referentes teóricos. Por ejemplo, a suponer que hay un trauma original del cual se derivan o suman los otros. Y como hay una gran cantidad de experiencias traumáticas contadas, Freud infiere que hay una serie de ramificaciones localizadas en instancias. ¿Qué instancias? Las que irá construyendo a lo largo de su obra: preconsciente, inconsciente. Infiere además un yo conciencia que resiste, se defiende, sofoca, censura, olvida el recuerdo traumatizante en tanto causa primera del padecimiento. Es importante anotar que estas defensas emergen en el dispositivo del tratamiento, por lo que queda la interrogante de si ellas son respuestas de la paciente al tratamiento o al médico. Freud supondrá que hay una transferencia de su neurosis al dispositivo. Otra forma de entenderlo es que los estilos retóricos son patrones relacionales prototípicos usados en diversos contextos, y que la psicoterapia ofrece un contexto para pensarlos y actualizarlos.

Los relatos de sufrimiento y sus conexiones con otras narraciones, como con ciertas palabras y formas de enunciar, son enigmáticas para Freud. Son descriptores que no son nada sin la 
intelección del médico que por abstracción sistematiza, da cuenta de cierta consistencia entre lo percibido como una expresión de la naturaleza y lo observado. Como refiere el historiador: "[...] ser visto y ser hablado comunican sin tropiezo en la verdad manifiesta de la enfermedad de la cual está allí precisamente todo el ser"(Foucault, 1999, p. 138). Esta última idea de Foucault es patente en la muestra que analizamos en tanto que cualquier elemento expresivo o comunicacional que tiene la paciente, tiene que ver con "su enfermedad", pues es una histeria. Otro ejemplo de que todo signo expresado por Emmy confirma la enfermedad asumida como diagnóstico, es cuando cita a Darwin, para explicar por analogía la derivación de la excitación del meneo de la cola del perro, y en donde lee que algunos síntomas corporales de la paciente, como el dolor, son por otros recuerdos de dolor, "símbolos mnémicos". La mirada aguda de Freud, le permite describir las formas expresivas de la paciente y a crear perfiles, conjeturas, hipótesis y teorías explicativas. Este esfuerzo por dar razón detallada de los signos en los relatos no es ajeno a su intención consciente como lo refiere en esta aclaración a la comunidad epistémica de su tiempo:

"[...] yo podría causar la impresión de que atribuyo excesivo peso al detalle de los síntomas y me pierdo en una superflua manía de interpretar signos. Pero he aprendido que el determinismo de los síntomas histéricos llega efectivamente hasta su más fina ejecución, y no se corre el riesgo de atribuirles con exceso un sentido" (Freud, 189395/1985, p. 112).

Bajo este descriptor también hay un principio epistémico propio de la ciencia: toda expresión de la naturaleza tiene una causa que se puede explicar y comprobar por las condiciones de su recurrencia.

Como se ve, Freud no oculta su aspiración de hombre de ciencia de su tiempo en tanto que siente el apremio de aportar al conocimiento. Pero ¿qué podemos objetar a Freud, desde la crítica que le hace Foucault respecto a su monólogo indefinido y vigilante? Quizá que, como en otros grandes inventos como en el mito del descubrimiento de la penicilina, la innovación y el ingenio, no está en la intención y poder atribuido al método de observación y la abstinencia o pureza descriptiva, sino en el fenómeno residual. El pensar consciente de Freud sigue los rigores propios del paradigma médico, en ese esfuerzo hay ciertas rendijas narrativas que develan de manera marginal la verdad del relato. Sin saberlo Freud deja entrever su preconsciente narrativo, el cual se evidencia en los juegos del lenguaje; por la fuerza de la locución, la ilocusión y la perlocusión. Freud relata: "[...] su ataque cesó frente al mensaje de su tía: que dijo "eso es abominable, una no podía tener tales ataques" (189395/1985, p. 75). La intención comunicativa del relato muestra que la tía hace una acción específica que detiene el acto, esa acción es una expresión verbal, un mandato de alguien que tiene poder de prohibir y sancionar. Y que el efecto de su mensaje es acatado por la niña. 
Este relato como los usos verbales que el mismo Freud aplica a la paciente en el tratamiento o en el momento de presentar el caso (como se ilustra en los cuadros 1 y 2 ), demuestran que más allá de la intencionalidad consciente de Freud, se entrevé la verdad del lenguaje. Freud supone que la efectividad para disminuir los síntomas, dolores o sufrimientos penden de su conocimiento sobre la histeria y el método hipnótico y catártico, pero en su desarrollo lo que deja entrever son el poder de la palabra, del lenguaje.

En su análisis final del caso (la epicrisis) se da cuenta que los avances logrados, no fueron consistentes tal como él esperaba. El punto ciego de Freud quizá radica en dejar de lado el preconsciente 5 propio y el dispositivo que le da consistencia a cualquier campo de sentido que en él se construye. El preconsciente de Freud, radica en su gramática, en el uso de las oraciones, la sintaxis y la prosodia con la cual se comunica (como se ejemplifica en el cuadro 2). Es claro con lo trabajado anteriormente, en el foco de análisis, que Freud en su presentación del caso discurre en un monólogo infinito, en donde el campo de sentido de la verdad de la paciente estará siempre en su mano. Por lo que, la técnica fundamental que usa en el tratamiento no es la hipnosis sino la retórica, la cual al parecer por los verbos que utiliza tiene como fin disuadir, persuadir, someter, sofocar, borrar las representaciones patológicas de la paciente. Freud, revela la fonética doliente de la paciente, pero esta no es nada sin el juego fonológico que hace como escucha, haciendo de esos actos paraverbales o corporales todo un campo de sentido que va ligando a las historias contadas por ella.

El fenómeno residual de Freud devela que ese cuerpo que observaba el clínico en los siglos XVIII y XIX, además era hablante; que estaba preñado de un mundo de sentidos y vivencias. Que las figuras retóricas que aparecen en las narraciones como el sapo, es un condensado de sentido que tiene efectos en el hablante, aunque ese signo no pueda ser aclarado por la conciencia o intención del investigador. Que hay un orden de los significados y ciertas reglas de decibilidad y de ocultamiento inevitable en el uso del lenguaje. Que el paciente ignorante del saber médico expresa su vivenciar por medio de narraciones, y que las repeticiones temáticas de las mismas generan un campo de sentido mayor, en la medida que los micro relatos se articulan unos con otros.

El significante oculto al narrador aparece también condensado en un tic o en una onomatopeya, o en alguna dolencia corporal. Este se revela gracias a que emergen insistentemente en el recuento, así como por la escucha e interpretación del médico que hace regresar palabras y conexiones entre los relatos. Freud al escuchar las historias busca orígenes materiales, objetivables, por eso supone traumas originarios o la verdad histórica; causalidad primera, la causa material y la causa eficiente del evento, y lo que encuentra, es un entramado de historias y fantasías a interpretar. La ilusión epistemológica de que todo 
trauma tiene una causa primera factible de ser explicada por el científico se enfrenta a otra más primaria a saber: para toda pregunta hay una respuesta; todo signo comunicacional es interpretable.

El desconcierto de Freud, al escuchar el dolor psíquico y evidenciar que el doliente no sabe dar razón de ello, se debe a que supone que el orden del discurso estaba regido por el pensamiento cartesiano, donde las ideas son claras y distintas. Por lo que al yo pienso de Descartes, Freud le sobrepone un sujeto intencional substante, y que era más determinante: un inconsciente, una segunda consciencia, un sujeto dividido y acallado, o un sujeto que ha fracasado en su intento de reprimir los eventos displacenteros ${ }^{6}$.

Cuando Freud presenta el caso de Emmy, cita frases textuales, quiere dar razón de su práctica, de su tratamiento hipnótico y catártico para la histeria, sin embargo, algo obstaculiza la curación sugestiva racional. Y aquellos avances que pudo haber logrado la paciente, fundamentalmente eran ofrendas de obediencia al médico, como reconocerá él mismo al pensar su caso en el subtema: la epicrisis. Refiere: "Entonces, ¿seguirá teniendo miedo a estos animales?, la respuesta fue: 'No... porque usted lo demanda'"' (Freud, 189395/1985, p. 117). Al develar al final del tratamiento que su técnica era infructuosa y que dependía de su autoridad, queda defraudado de la hipnosis, pero también de la paciente, a la cual califica, párrafos después, como obstinada, por retener contra la sugestión sus síntomas, sin embargo, tan dócil cuando se trataba de acatar sugerencias sin importancia que no tenían que ver con la enfermedad. Además, en nota al pie sentencia que sólo un cerebro patológico buscaría: "[...] la obstinada perseverancia de los síntomas patológicos porque estos últimos tienen fundamento más profundo y son inaccesibles al análisis [...]" (Freud, 1893-95/1985, p. 117).

Al problematizar este encuentro de Freud con la Sra. Emmy, se evoca el diálogo platónico del Menón, en el cual por medio de la dialéctica Sócrates quiere evidenciar la reminiscencia, bajo el principio de que el esclavo tiene conocimiento sólo que no se acuerda. Pero basta saber preguntar para hacerlo emerger. Freud pretende mostrar la verdad diagnóstica de la histeria, y dar razón de por qué el enfermo no recuerda todo lo vivido, sobre todo aquello que le fue displacentero. $Y$ bastará con proporcionarle sugerencias hipnóticas para evidenciar que sí sabe. Entre el diálogo Freudiano y el Socrático en el Menón, el segundo es franco, pone en escena bajo comedia, cómo se genera un saber; cómo, el forzamiento de la palabra del amo hace hablar al esclavo para producir el conocimiento útil. Y cómo éste saber, bajo pretensión de verdad está coligada al lugar y palabra del amo. Freud consciente y seguro de la verdad médica, usaba la técnica hipnótica, con supuestos epistemológicos en miras de dar consistencia al paradigma representacional, en donde las ideas tienen cierto 
acomodo por su proximidad y temporalidad de acuerdo a lo percibido. Pero es inconsciente de lo que hace lingüísticamente cuando aplica el tratamiento, como en la presentación del caso.

En su escotoma habita la labilidad de la verdad del amo. La cual le regresa de manera invertida por el efecto del espejo. Esa imagen es inadmisible para el amo, y es leída como resistencia a su poder de verdad, como se ilustra en el siguiente relato: "Al preguntarle su opinión sobre el origen de sus dolores de estómago, respondió, incapaz de disimular: «Creo que se deben a mi angustia, pero sólo porque usted lo dice»" (Freud, 1893-95/1985, p. 101).

Este escrito está acotado a una muestra de análisis por lo que queda pendiente otros estudios sistemáticos para corroborar si con los años Freud dejó de pensar el caso como médico o si pudo mover su escucha al servicio de la clínica más que a los intereses del investigador.

Basados en el análisis aquí presentado se puede sostener que la pretensión de verdad de Freud se rige insoslayablemente por la ley del lenguaje, la cual, al serle ajena a su paradigma de pensamiento, la manda a lo ignoto. La consciencia no puede dar cuenta de todos los procesos percibidos y todo intento de apalabramiento 7 de la realidad, es insuficiente en tanto que el campo de sentido no sólo se genera por la ilocución sino además por la perlocución.

\section{Conclusiones}

Para terminar de redondear lo analizado en este escrito, a continuación, se analiza un concepto fundamental que usa Freud para explicar la histeria.

Freud liga al diagnóstico de histeria, el término: vivencia traumática. En la comunicación preliminar y la epicrisis del caso analizado, Freud justifica la analogía, como ya se decía arriba, entre la histeria corriente y la neurosis traumática. Supone en este inicio de su teorización que la causa eficiente se sostiene por su afecto en la vivencia donde se han suscitado horror, angustia, vergüenza, dolor psíquico, y de la sensibilidad de la persona. $Y$ evidenciará que esos recuerdos displacenteros que se han tratado de evitar son fracasos de sofocación que emergen en dolencias corporales u otros síntomas desplazados. Hay afectos que emergen desfigurados en otros eventos o desplazados al cuerpo, porque hay cierto proceso disociativo, se escinde el sujeto, y el saber reprimido emerge en el estado de hipnosis, y en su primera apuesta de este tiempo, el recuerdo y la abreacción del afecto es el camino para la cura. 
Más tarde en las primeras Conferencias de psicoanálisis, agrega que el sentido económico del trauma radica en: "[...] un exceso tal en la intensidad de estímulo que su tramitación o finiquitación \{Aufarbeitung\} por las vías habituales y normales fracasa, de donde por fuerza resultan trastornos duraderos para la economía energética" (1917/1984a, p. 252). Y agregará un desarrollo teórico sobre las series complementarias como precursores de la neurosis traumática. Ya después de describir las variables: fijación libidinal (constitución sexual prehistórica y vivenciar infantil) y el vivenciar accidental actual. Terminará reconociendo que todos somos neuróticos, pues las formaciones del síntoma pueden pesquisarse en las personas normales. Más tarde en el Moisés y la religión monoteísta reconocerá como "[...] traumas a esas impresiones de temprana vivencia, olvidadas luego" (Freud, 1939/1986b, p. 70). También en este texto asume las series complementarias como precursoras de la experiencia traumática. Y aporta una nueva definición:

Estos tres puntos -aparición temprana dentro de los primeros cinco años, olvido y contenido sexual-agresivo- se copertenecen de manera estrecha. Los traumas son vivencias en el cuerpo propio o bien percepciones sensoriales, las más de las veces de lo visto y oído, vale decir, vivencias o impresiones (Freud, 1939/1986b, p. 72).

Esta última definición tiene un paralelismo con algo que refiere Freud en el Manuscrito $M, a$ saber: "Las fantasías se generan por una conjunción inconsciente entre vivencias y cosas oídas, de acuerdo con ciertas tendencias. Estas tendencias son las de volver inasequible el recuerdo del que se generaron o pueden generarse síntomas" ${ }^{8}$ (Freud, 1897/1986a, p. 293).

En esta complejización del concepto se releva la oscilante o doble postura de Freud entre la mirada médica y su admisión al campo del lenguaje, al símbolo, por su fuerza de imposición en el sujeto. La mirada clínica lo lleva a sostener el juego analógico de la palabra trauma de lo físico al psíquico, lo cual deriva en una inferencia generalizante, "todos estamos enfermos" (1917/1984b, p. 326). En esto se evidencia lo que los historiadores enfatizan a saber, que detrás de la construcción teórica de Freud prevalece la lectura antropopatológica. Ya que, además, ofrece hipótesis que devienen de perspectivas evolutivas como las series complementarias y el presupuesto de los esquemas filogenéticos. Pero innova cuando hace un isomorfismo entre el concepto de fantasía y el de trauma.

Sostendrá que la represión es el precursor del síntoma, y ésta no es sino por un mal arreglo, en donde falla la censura en la pretensión de adecuarse a los ideales sociales. Con estas últimas consideraciones da importancia a cómo se construye el campo de sentido, en tanto que la vivencia traumática como recuerdo fantasmático, está signada no sólo por la reacción displacentera del cuerpo (afecto pasivo o la fuerza de respuesta energética desbordante por 
la imposición de la vivencia), sino, además, por aquello que da sentido por lo visto y lo oído (representación cosas/representación palabra).

Como vemos la mirada clínica de Freud cual hombre de su época fuerza en su escritura con voluntad de poder la idea sostenida por algunos filósofos en occidente, a saber: el carácter del humano es ser enfermo ${ }^{9}$. De frente a tal principio ofrece esta intelección: la descripción neurótica, patológica del ser humano. Pero para sostener tal apuesta se enfrenta al límite de la mirada médica en tanto que esta no es posible sin aparato lingüístico, y en su pretensión de evidenciar el fenómeno sintomático revela los juegos de lenguaje que sostienen su observación y su escritura, así como la sintaxis y la prosodia de la paciente. Por lo que la arqueología médica, como bien infiere Reeder (1992), se vuelve hermenéutica. Si se tiene como presupuesto que la verdad se sostiene por los juegos del lenguaje, la escucha analítica, la técnica también se trastoca pues más que de recordar o buscar una huella objetiva en la historia, se trata de ejercer el saber de la erística, para la resignificación (Lacan,1990).

Concluyendo, se refería anteriormente en el apartado de problematización, que Foucault interroga al psicoanálisis por ser una ciencia de la observación y la clasificación, en tanto que en la práctica no hay un diálogo sino un silenciamiento del paciente a quien se somete, y supone que el psicoanálisis exorcizará esa preponderancia de la mirada médica cuando "[...] haya sustituido su magia silenciosa por los poderes del lenguaje" (Foucault, 1998b, p.228). El reto que lanza Foucault implica no sólo transformar la práctica sino replantear el concepto de historia y de verdad en psicoanálisis.

Como se advierte en este escrito, Freud inicia una nueva práctica innovadora para el siglo $X I X$ y principios del $X X$, y es gracias al uso de la técnica y a replanteamientos posteriores que ese inédito adquiere actualidad. Por lo que, podemos aseverar que la respuesta a la interpelación de Foucault ya había sido dada por uno de sus contemporáneos. Lacan recrea los conceptos freudianos no siguiendo las hipótesis o metáforas del médico del siglo XVIIIXIX, sino las rutas propias del lenguaje. Lacan profiere en Función y campo de la palabra, que el inconsciente y el síntoma están estructurados como lenguaje y que, "[...] es aquella parte del discurso concreto en cuanto transindividual que falta a la disposición del sujeto para restablecer la continuidad de su discurso consciente" (Lacan, 1990, p. 248). Más tarde agregará con mayor claridad que el preconsciente, está en la sintaxis misma ${ }^{10}$. Por lo que el inconsciente está en el campo del Otro, y más que un determinante acabado, es un porvenir incierto, si se permite que la palabra creadora circule hacia "lo no nacido", "lo no realizado" (Lacan, 2010, p. 30), pero que está en ciernes en lo indecible, en el predecir y el pordecir. Por lo que hará un viraje interpretativo de la fijación libidinal, al considerarla narrativamente como "página de vergüenza que se olvida o que se anula, o de gloria que obliga" (Lacan,1990, 
p. 251). Lacan no deja de lado los aciertos freudianos, reconoce que muchas veces lo olvidado se recuerda en los actos o en su evitación, y la anulación en el discurso (un juicio adverso) se opone a lo que se expresa en otra parte, como sucede cuando se queda atrapado en el reflejo especular. Por lo que interpreta que la opacidad del traumatismo en Freud estará entendida como la resistencia a la significación (Lacan, 2010) ${ }^{11}$. En este campo explicativo, Lacan reconoce como muy significativo ese momento de trasmisión del poder del sujeto al Otro, garante de la palabra y de la sentencia de verdad. El poder de la mirada y de la escucha gracias a los inéditos freudianos y los desarrollos posteriores no pertenecerán más al amomédico, sino al discurso emergente en el dispositivo analítico, en el cual se deciden y determinan los deseos y padecimientos historizados.

\section{REFERENCIAS}

Echeverría, R. (2003). Ontología del Lenguaje. Santiago, Chile: J. C. Sáez Editores.

Foucault, M. (1970). Nietzsche, Freud, Marx. Barcelona, España.

Foucault, M. (1980). Microfísica del Poder. Madrid: Piqueta.

Foucault, M. (1995). Las palabras y las cosas. Ciudad de México, México: SXXI.

Foucault, M. (1996a). Historia de la sexualidad. T. I. Voluntad de Saber. Ciudad de México, México: S. XXI.

Foucault, M. (1996b). Tecnologías del Yo. Barcelona, España: Paidós.

Foucault, M. (1996c). La verdad y las formas jurídicas. Barcelona, España: Gedisa.

Foucault, M. (1998a). Historia de la locura en la época clásica. T. I. Ciudad de México: México: Fondo de Cultura Económica.

Foucault, M. (1998b). Historia de la locura en la época clásica. T. Il. Ciudad de México, México: Fondo de Cultura Económica.

Foucault, M. (1999). El nacimiento de la clínica. Ciudad de México, México: S. XXI.

Freud, S. (1984a). Conferencias de introducción al psicoanálisis. 18a conferencia, La fijación al trauma, lo inconsciente. En J. L. Etcheverry (Traduc.), Obras Completas: Sigmund Freud (Vol. 16, pp. 250-261). Buenos Aires, Argentina: Amorrortu. (Trabajo original publicado en 1917).

Freud, S. (1984b). Conferencias de introducción al psicoanálisis. $23^{\mathrm{a}}$ conferencia, Los caminos de la formación del síntoma. En J. L. Etcheverry (Traduc.), Obras Completas: Sigmund Freud (Vol. 16, pp. 326-343). Buenos Aires, Argentina: Amorrortu. (Trabajo original publicado en 1917).

Freud, S. (1986a). Manuscrito M. En J. L. Etcheverry (Traduc.), Obras Completas: Sigmund Freud (Vol. 1, pp. 292-295). Buenos Aires, Argentina: Amorrortu (Trabajo original publicado en 1897). 
Freud, S. (1986b). Moisés y la religión monoteísta. En J. L. Etcheverry (Traduc.), Obras Completas: Sigmund Freud (Vol. 23, pp. 1-132). Buenos Aires, Argentina: Amorrortu. (Trabajo original publicado en 1939).

Freud, S \& Breuer, J. (1985). Estudios sobre la histeria. En J. L. Etcheverry (Traduc.), Obras Completas: Sigmund Freud (Vol. 2, pp. 1-26o). Buenos Aires, Argentina: Amorrortu. (Trabajo original publicado en 1893-95).

Lacan, J. (1990). Función y campo de la palabra y del lenguaje en psicoanálisis. En Lacan, J., Escritos I (pp.227-310). España: Biblioteca Nueva.

Lacan, J. (2010). Los cuatro conceptos fundamentales en psicoanálisis. Buenos Aires, Argentina: Paidós.

Laín, P. (1958). La empresa de ser hombre. Madrid, España: Revista de Occidente.

Laín, P. (1978a). Historia de la Medicina. Madrid, España: Salvat.

Laín, P. (1978b). La curación por la palabra en la antigüedad clásica. Madrid, España: Revista de Occidente.

Lothane, Z. (2009). Dramatology in life, disorder, and psychoanalytic therapy: A further contribution to interpersonal psychoanalysis. International Forum of Psychoanalysis, 135-148. doi: 10.1080/08037060903116154

Nasio, D. (2001). Los más famosos casos de psicosis. Buenos Aires, Argentina: Paidós.

Reeder, J. (1992). Freud's Narrative. From Case History to Life Story. International Forum of Psychoanalysis, 51-60.

Santander, P. (2011). Por qué y cómo hacer análisis de discurso. Cinta de Moebio, 207-224. doi: 10.4067/S0717-554X2011000200006

Stake, R. E. (1999). Investigación con estudio de casos. Madrid, Morata.

Vallejo, M. (2006). Incidencias en el psicoanálisis de la obra de Michel Foucault. Buenos Aires, Argentina: Letra viva.

Original recibido con fecha: 3/6/2019 Revisado: 22/10/2019 Aceptado: 30/10/2019

NOTAS:

\footnotetext{
${ }_{1}$ Textualmente lo refiere asi: "Dramatology is a methodological concept applicable to interpersonal relationships in health, neurosis, and the analytic situation. Since drama emphasizes emotion, "dramatic" and "dramatize" became colloquialisms connoting a spectrum from striking in appearance and effect to emotionalism deemed excessive or inappropriate, as in "theatrical," "histrionic," and "melodramatic". (Lothane, 2009, p. 136).

2 Se está parafraseando la obra de Austin, ¿Cómo hacer cosas con palabras?

${ }^{3}$ Las explicaciones conceptuales de Freud también tratan de cumplir con argumentaciones exhaustivas basadas en aspiraciones científicas en su tiempo, a saber: la explicación dinámica, mecanicista y energética. Ya no se trata de los humores de Empédocles que refiere Galeno, sino de mecanismos, de la materia y energía que no se destruye, sino que se transforma.

${ }^{4}$ Características propias de la mirada diagnóstica del médico, como refiere Foucault, (1999).
} 


\begin{abstract}
${ }^{5}$ Siguiendo a Lacan, asumimos que el preconsciente es la sintaxis. Este punto se desarrolla más adelante.
${ }^{6}$ Visto desde aquí lo que Freud hace retóricamente con el caso al develar una segunda conciencia, un saber allende el pensar consciente es contra-argumentar, tratar de desmontar la proposición racionalista de su propia mirada de médico, su propio escotoma epistémico.

7 No se puede decir nada en plenitud; cada expresión o declaración a la vez que devela, que apalabra deja otro elemento acallado atrapado en la opacidad (miento) del decir.

${ }^{8}$ También dirá en la Carta 84: [...] "lo que en la época prehistórica es visto, da por resultado el sueño; lo que en ella es oído, las fantasías; y lo que en ella es vivenciado sexualmente, las psiconeurosis. La repetición de lo vivenciado en esa época sería en sí y por sí un cumplimiento de deseo; y un deseo reciente sólo llevaría al sueño cuando pudiera ponerse en conexión con un material de ese período prehistórico [...] (Freud, 1983a, p. 316).

${ }^{9}$ Los filósofos la refieren como metáfora, como estética dramática: falta existencial, Freud la sostiene desde la mirada médica.

${ }^{10}$ Dirá a la letra: "La sintaxis, por supuesto, es preconsciente. Pero lo que escapa al sujeto es que su sintaxis está relacionada con la reserva inconsciente que escapa al sujeto. Cuando el sujeto cuenta su historia, actúa, latente, lo que rige a esa sintaxis, y la torna cada vez más ceñida. ¿Ceñida con respecto a qué? A lo que Freud, desde el principio de su descripción de la resistencia psíquica, llama un núcleo". Lacan, (2010, p. 76).

${ }^{11}$ Supongo que Lacan se refiere a que en todo intento de simbolización hay un límite dado por lo real en tanto insondable, cuando Freud en el caso aquí trabajado advierte: "Puntualicé, tomando ejemplos de la vida corriente, que una investidura así de una representación con afecto no tramitado conlleva siempre cierto grado de inaccesibilidad asociativa, de inconciliabilidad con nuevas investiduras" (Freud, 1983b, p.108).
\end{abstract}

